\title{
Structural Insights into the Molecular Basis Responsible for the Effects of Immobilization on the Kinetic Parameters of Glyceraldehyde-3-Phosphate Dehydrogenase from Trypanosoma cruzi and Human
}

\author{
Rafael V. C. Guido, ${ }^{a}$ Carmen L. Cardoso, ${ }^{b}$ Marcela C. de Moraes, ${ }^{c}$ \\ Adriano D. Andricopulo, ${ }^{a}$ Quezia B. Cass ${ }^{*, c}$ and Glaucius Oliva* \\ ${ }^{a}$ Laboratório de Química Medicinal e Computacional, Centro de Biotecnologia Molecular \\ Estrutural, Instituto de Física de São Carlos, Universidade de São Paulo, \\ Av. Trabalhador São-Carlense 400, 13560-970 São Carlos-SP, Brazil \\ ${ }^{b}$ Departamento de Química-Faculdade de Filosofia, Ciências e Letras de Ribeirão Preto, \\ Universidade de São Paulo, Av. Bandeirantes 3900, 14040-901 Ribeirão Preto-SP, Brazil \\ 'Departamento de Química, Universidade Federal de São Carlos, CP 676, \\ 13565-905 São Carlos-SP, Brazil
}

\begin{abstract}
O desenvolvimento de métodos rápidos e eficazes para a identificação de novas moléculas bioativas é fundamental para o processo de descoberta e planejamento de fármacos. A integração de um sistema de cromatografia liquida de alta eficiência (CLAE), com biorreatores como fase estacionária (IMER) é uma estratégia atrativa e versátil para a triagem de coleções de compostos visando à identificação de novos agentes terapêuticos. Os parâmetros cinéticos da enzima imobilizada gliceraldeído-3-fosfato desidrogenase (GAPDH) de Trypanosoma cruzi e humana foram determinados (T. cruzi: $K_{\mathrm{M}}^{\mathrm{G} 3 \mathrm{P}}=0.50 \mathrm{mmol} \mathrm{L}^{-1} ; K_{\mathrm{M}}{ }^{\mathrm{NAD}+}=0.67 \mathrm{mmol} \mathrm{L}^{-1}$; humana: $\left.K_{\mathrm{M}}{ }^{\mathrm{GP}}=3.7 \mathrm{mmol} \mathrm{L}^{-1} ; K_{\mathrm{M}}^{\mathrm{NAD}+}=0.75 \mathrm{mmol} \mathrm{L}^{-1}\right)$ e comparados com aqueles observados em solução (T. cruzi: $K_{\mathrm{M}}^{\mathrm{G} 3 \mathrm{P}}=0.42 \mathrm{mmol} \mathrm{L}^{-1} ; K_{\mathrm{M}}^{\mathrm{NAD}+}=0.26 \mathrm{mmol} \mathrm{L}^{-1}$; humana: $K_{\mathrm{M}}^{\mathrm{G} 3 \mathrm{P}}=0.16 \mathrm{mmol} \mathrm{L}^{-1}$; $K_{\mathrm{M}}^{\mathrm{NAD+}}=0.18 \mathrm{mmol} \mathrm{L}^{-1}$ ). Os resultados indicaram uma diminuição na afinidade das enzimas imobilizadas, entretanto, os elementos estruturais necessários para o processo de reconhecimento molecular e atividade biológica permaneceram inalterados, aumentando a estabilidade das enzimas. Além disso, a análise estrutural forneceu dados moleculares importantes envolvidos nos efeitos da imobilização sobre as interações entre ligante e receptor e, consequentemente, sobre a atividade enzimática e parâmetros cinéticos.
\end{abstract}

The development of fast and reliable methods for the identification of new bioactive compounds is of utmost importance to boost the process of drug discovery and development. Immobilized enzyme reactors (IMERs), integrated with high performance liquid chromatography (HPLC), are attractive and versatile tools for screening collections consisting of natural products and synthetic small molecules. Standard kinetic parameters of the immobilized enzyme glyceraldehyde-3-phosphate dehydrogenase (GAPDH) from both Trypanosoma cruzi de and human have been determined (T. cruzi: $K_{\mathrm{M}}{ }^{\mathrm{G} 3 \mathrm{P}}=0.50 \mathrm{mmol} \mathrm{L}^{-1} ; K_{\mathrm{M}}{ }^{\mathrm{NAD}+}=0.67 \mathrm{mmol} \mathrm{L}^{-1}$; humana: $\left.K_{\mathrm{M}}^{\mathrm{G} 3 \mathrm{P}}=3.7 \mathrm{mmol} \mathrm{L}^{-1} ; K_{\mathrm{M}}^{\mathrm{NAD+}}=0.75 \mathrm{mmol} \mathrm{L}^{-1}\right)$, and comparisons of these values with those of the parasite and human free enzymes indicate a decrease in the affinity for the immobilized system (T. cruzi: $K_{\mathrm{M}}^{\mathrm{G} 3 \mathrm{P}}=0.42 \mathrm{mmol} \mathrm{L}^{-1} ; K_{\mathrm{M}}^{\mathrm{NAD}+}=0.26 \mathrm{mmol} \mathrm{L}^{-1}$; humana: $K_{\mathrm{M}}^{\mathrm{G} 3 \mathrm{P}}=0.16 \mathrm{mmol} \mathrm{L}^{-1}$; $\left.K_{\mathrm{M}}{ }^{\mathrm{NAD+}}=0.18 \mathrm{mmol} \mathrm{L}^{-1}\right)$. Interestingly, despite the kinetic differences between the two systems, the immobilized GAPDHs retained the required structural requirements for molecular recognition and biological activity, increasing the stability the enzyme. In the present work, we described an integrated structural analysis which has provided important insights into the molecular basis underlying the effects of immobilization on the ligand-receptor interactions and consequent enzymatic activity and kinetics parameters.

Keywords: immobilized enzymes reactors, enzymes, kinetic parameters, structural analysis, drug design

*e-mail: quezia@dq.ufscar.br, oliva@ ifsc.usp.br 


\section{Introduction}

The current drug discovery paradigm strongly relies on knowledge, creativity, innovation, and a combination of modern strategies and technologies. ${ }^{1}$ Immobilized enzyme reactors (IMERs) have recently been considered with great interest by the scientific community as a screening method capable of identifying hits and lead candidates. $^{2}$ The use of IMERs, integrated with high performance liquid chromatography (HPLC), represents an attractive and versatile approach for screening either highly diverse or focused collections of small molecule compounds for binding to major molecular drug targets. This method allows the rapid screening of both natural products and synthetic compounds for biological activity, enabling more compounds to be tested against a particular or a set of macromolecular targets. Other advantages of the IMER system include its high stability, reliability and high performance, which are important components for increasing the accuracy and reproducibility of the experimental measurements while minimizing the costs and time of data collection and analysis when compared to standard kinetic enzymatic assays in free solution. ${ }^{3}$ Several studies of enzyme immobilization methods in biocatalysis have been reported, emphasizing the applicability and importance of this technology in biotechnology and drug design..$^{3-5}$ For instance, (i) on-line synthesis; (ii) identification of metabolites; (iii) purification and determination of chiral molecules; and (iv) identification of new hits and leads. Particularly, immobilized enzymes can be implemented as an alternative high-throughput screening (HTS) method aimed at identifying novel drug candidates for the treatment of several life-threatening diseases. $^{6-8}$

Neglected tropical diseases are widely distributed throughout the tropical and subtropical regions of the world, with significant social and economic impact. ${ }^{9,10}$ Chagas' disease, caused by the parasite Trypanosoma cruzi, is a parasitic infection widespread in the Americas, from the great lakes of North America to Southern Patagonia, with devastating consequences in terms of human morbidity and mortality. ${ }^{11}$ Glyceraldehyde-3phosphate dehydrogenase (GAPDH, EC 1.2.1.12), a key enzyme involved in the glycolytic pathway of $T$. cruzi, catalyzes the reversible oxidative phosphorylation of the substrate glyceraldehyde-3-phosphate (GAP) to 1,3-diphosphoglycerate in the presence of the cofactor $\mathrm{NAD}^{+}$and inorganic phosphate. ${ }^{12,13}$ Crystallographic and molecular modeling studies revealed significant structural differences between the parasite enzyme and its human homologue that can be explored for the development of selective inhibitors with therapeutic potential. ${ }^{14-22}$ Considering the fact that selectivity is an essential property in the design of novel chemotherapeutic agents, we have recently developed robust and efficient IMERs for the GAPDHs from both T. cruzi and human. ${ }^{23,24}$

The kinetics parameters are important to probe the influence of the immobilization on the enzyme's structure, ${ }^{25,26}$ given that immobilization may impact the binding affinity of substrates and inhibitors and thus, the catalytic properties. ${ }^{27-29}$

As part of our research program aimed at understanding the mechanisms underlying affinity and selectivity, we have evaluated the kinetic parameters of the free and immobilized GAPDHs from T. cruzi and human. Subsequently, we have correlated the kinetic data with the three-dimensional (3D) structures available in protein databank (PDB) in order to identify the structural elements related to the differences observed. This integrated analysis provided important insights into the molecular basis underlying the effects of immobilization on the kinetic parameters.

\section{Experimental}

\section{Materials}

Recombinant T. cruzi GAPDH was prepared and purified according to the previously reported procedure. ${ }^{30}$ Human GAPDH crystalline derived from human erythrocyte, D-glyceraldehyde-3-phosphate (G3P) and $\beta$-nicotinamide adenine dinucleotide $\left(\mathrm{NAD}^{+}\right)$were purchased from Sigma Aldrich (St. Louis, MO, USA). Buffer components and all chemical materials used during the immobilization procedure were of analytical grade supplied by Sigma or by Merk (Darmstdt, Germany). All solvents were HPLC grade purchased from J.T. Baker (Phillipsburg, USA). All experiments used water purified with a Millipore Milli-Q system (Millipore, São Paulo, Brasil). The mobile phases were prepared daily. Fusedsilica capillary for electrophoresis $(0.375 \mathrm{~mm} \times 0.10 \mathrm{~mm})$ used to immobilize the enzyme and prepare the IMERs was purchased from Polymicro Technologies (Phoenix, AZ, USA). The Luna - octyl silica (10 $\mu \mathrm{m}, 100 \AA)$ and the spherex- Diol OH silica $(10 \mu \mathrm{m}, 100 \AA)$ were supplied by Phenomenex (Torrance, CA, USA). Before their use for HPLC analysis, the buffers solutions were filtered through cellulose nitrate membrane filters $(0.45 \mu \mathrm{m})$ purchased from Phenomenex. Dialysis and concentration of enzymatic solution was carried out using a $30 \mathrm{~mL}$ Amicon concentrator (Millipore, Billerica, MA) and an Eppendorf centrifuge (Eppendorf Instruments, Enfield, USA). 


\section{Methods}

\section{Immobilization of GAPDH onto capillary}

T. cruzi and human GAPDHs were covalently immobilized onto an electrophoresis fused-silica capillary based on the procedures previously described..$^{23,24}$

\section{Chromatographic and spectrophotometric systems}

Two modular HPLC systems were setup in order to carry out the on-line studies. The chromatographic experiments were performed using a Shimadzu HPLC system (Shimadzu, Kyoto, Japan), which consisted of the two LC 10 AD VP pumps with one of the pumps having a valve FCV-10AL for selecting solvent, a UV-Vis detector (SPD-M10AV VP), an autosampler equipment with a $500 \mathrm{~L}$ loop (SIL 10 AD VP). The column containing the immobilized GAPDH enzyme (GAPDH-IMER) was coupled on-line to an octyl column (Luna-Phenomenex ${ }^{\circledR}, 100 \AA, 10 \mu \mathrm{m}, 10 \mathrm{~cm} \times 0.46 \mathrm{~mm}$ i.d.). A six-way switching sample-valve Valco Nitronic 7000 EA (Supelco, St. Louis, MO, USA) was used to connect the two columns. The data were acquired on a Shimadzu SCL 10 AVP system interface with a computer equipped with Shimadzu-Lc solutions (Lcsolution 2.1) software (Shimadzu, Kyoto, Japan). The free enzymes were evaluated using a Shimadzu (Shimadzu, Kyoto, Japan) UV- 1650 PC spectrophotometer, with a computer equipped with a UV Probe (Kinetics) software version 1.10 for data collection. Spectrometric determinations of free GAPDHs were carried out using a Cary 100 Bio UV/V equipped with a Peltierthermostated multicell changer and a temperature controller.

\section{Kinetics measurements of the free GAPDH}

All enzymatic assays were carried out in triplicate at $25^{\circ} \mathrm{C}$. The enzymatic activities of soluble $T$. cruzi and human GAPDHs were evaluated by measuring the biochemical reduction of $\mathrm{NAD}^{+}$to $\mathrm{NADH}(\lambda=340 \mathrm{~nm}) \cdot{ }^{30,31}$ Enzymatic activity was calculated from the initial slope of the curve obtained during $30 \mathrm{~s}$ of the reaction. $\mathrm{NAD}^{+}$concentrations varied from 0.25 to $15 \mathrm{mmol} \mathrm{L}^{-1}$ and G3P concentrations from 0.15 and $15 \mathrm{mmol} \mathrm{L}^{-1}$. The parameters for $\mathrm{NAD}^{+}$were determined under saturating conditions of G3P $\left(800 \mu \mathrm{mol} \mathrm{L}^{-1}\right)$, whereas the parameters for G3P were determined under saturating concentrations of $\mathrm{NAD}^{+}\left(800 \mu \mathrm{mol} \mathrm{L}{ }^{-1}\right)$.

\section{T. cruzi GAPDH}

The $500 \mu \mathrm{L}$ reaction mixture contained $445 \mu \mathrm{L}$ of triethanolamine buffer (100 mmol L-1, pH 7.5, containing $1.0 \mathrm{mmol} \mathrm{L}{ }^{-1}$ EDTA, $1.0 \mathrm{mmol} \mathrm{L}{ }^{-1}$ PMSF, $1.0 \mathrm{mmol} \mathrm{L}{ }^{-1} \beta$-mercaptoethanol), $15 \mu \mathrm{L}$ of $30 \mathrm{mmol} \mathrm{L}^{-1}$ $\mathrm{Na}_{2} \mathrm{HAsO}_{4} \cdot 7 \mathrm{H} 2 \mathrm{O}, 5 \mu \mathrm{L}$ of $\mathrm{NAD}^{+}, 30 \mu \mathrm{L}$ de G3P. The reaction was initiated with the addition of the $5 \mu \mathrm{L}$ enzyme (20 nmol L-1).

\section{Human GAPDH}

The $500 \mu \mathrm{L}$ reaction mixture contained $460 \mu \mathrm{L}$ of Tris- $\mathrm{HCl}$ buffer $\left(50 \mathrm{mmol} \mathrm{L}^{-1}, \mathrm{pH} \mathrm{8.6,} \mathrm{containing}\right.$ $1.0 \mathrm{mmol} \mathrm{\textrm {L } ^ { - 1 }} \beta$-mercapthoetanol, $30 \mathrm{mmol} \mathrm{L}^{-1}$ $\mathrm{Na}_{2} \mathrm{HAsO}_{4} \cdot 7 \mathrm{H} 2 \mathrm{O}, 1.0 \mathrm{mmol} \mathrm{L}-1$ EDTA) $30 \mu \mathrm{L}$ de G3P, $5 \mu \mathrm{L} \mathrm{NAD}^{+}$. The reaction was initiated with the addition of the $5 \mu \mathrm{L}$ enzyme $\left(20 \mathrm{nmol} \mathrm{L}^{-1}\right)$.

\section{Kinetics studies of the immobilized enzyme}

The enzymatic activity of GAPDH-IMERs format was evaluated employing the multidimensional chromatographic system. ${ }^{23,24}$ Kinetic studies were performed under saturating conditions for $\mathrm{NAD}^{+}$or G3P as detailed below.

\section{T. cruzi GAPDH-IMER}

Solutions with $\mathrm{NAD}^{+}$concentrations ranging from 0.10 to $12.5 \mathrm{mmol} \mathrm{L}^{-1}$ and $\mathrm{G} 3 \mathrm{P}$ concentrations between 0.10 and $12.5 \mathrm{mmol} \mathrm{L}^{-1}$ were injected in duplicate. The kinetic constants for $\mathrm{NAD}^{+}$were determined under saturating conditions of G3P $\left(7.5 \mathrm{mmol} \mathrm{L}^{-1}\right)$ while the parameters for $\mathrm{G} 3 \mathrm{P}$ were determined at saturating concentrations of $\mathrm{NAD}^{+}$ $\left(10 \mathrm{mmol} \mathrm{L}^{-1}\right)$. Samples were injected in duplicate $(15 \mu \mathrm{L}$, flow rate: $0.05 \mathrm{~mL} \mathrm{~min}^{-1}$; injection time: $2 \mathrm{~min}$ ) following the chromatographic conditions previously specified. ${ }^{23}$

\section{Human GAPDH-IMER}

Solutions with $\mathrm{NAD}^{+}$concentrations ranging from 0.10 to $20 \mathrm{mmol} \mathrm{L}^{-1}$ and $\mathrm{G} 3 \mathrm{P}$ concentrations between 0.20 and $20 \mathrm{mmol} \mathrm{L}^{-1}$ were injected in duplicate. The parameters for $\mathrm{NAD}^{+}$were determined under saturating conditions of G3P (7.5 mmol L-1) while the parameters for G3P were determined at saturating concentrations of $\mathrm{NAD}^{+}$ (10 $\left.\mathrm{mmol} \mathrm{L}^{-1}\right)$. Samples were injected in duplicate $(15 \mu \mathrm{L}$; flow rate: $0.05 \mathrm{~mL} \mathrm{~min}{ }^{-1}$; injection time: $2 \mathrm{~min}$ ) following the chromatographic conditions previously specified. ${ }^{24}$

\section{Data analysis}

SigmaPlot software was used to determine the kinetic parameters for the studied systems. Non-linear regression analysis using five independent measurements 
(mean \pm S.D.) of initial velocity for substrate or cofactor was employed for kinetic evaluation (analyses based on 15 points collected experimentally).

\section{Results and Discussion}

\section{Kinetics parameters}

The kinetic parameters for the free enzyme in solution and for the immobilized format were evaluated for the GAPDH substrate and cofactor, G3P and $\mathrm{NAD}^{+}$, respectively. The kinetic parameters of the T. cruzi $(T c \mathrm{GAPDH})$ and human (HuGAPDH) GAPDHs were determined by systematic variation of the concentrations of the substrate $\left(\mathrm{G} 3 \mathrm{P}\right.$ or $\left.\mathrm{NAD}^{+}\right)$, while all other components were kept at constant concentrations. Stock solutions of substrate and cofactor were prepared at the highest experimentally reasonable concentration. Serial dilutions were then made from these stocks to obtain a curve of initial velocity versus substrate concentration (Michaelis-Menten plot). Substrate and cofactor concentrations required for $15-85 \%$ enzymatic activity of GAPDH were used for kinetic evaluation. Nonlinear curve-fitting regression analysis was applied in order to determine the $K_{\mathrm{M}}$ and $V_{\text {MAX }}$ values from the collected data of five independent experiments. The results are presented in Table 1, Figure 1 and Figure 2.

The covalent immobilization of the GAPDH (T. cruzi and human) retained the enzymatic activity. As can be seen in Figure 1 and 2, the immobilized enzymes are capable of catalyzing the oxidative phosphorylation of the G3P in the presence of the cofactor $\mathrm{NAD}^{+}$. The reaction rate increases as a function of the cofactor concentration and tends to proceed to nearly complete conversion of substrate to product (data not shown). Additionally, the IMER systems exhibited highly similar kinetic parameters compared to those observed previously, ${ }^{23,24}$ thereby confirming the accuracy and reproducibility of the developed methods, which are essential elements to be addressed.

The $K_{\mathrm{M}}$ values of the immobilized parasite enzyme (TcGAPDH-IMER) for both G3P and $\mathrm{NAD}^{+}$are in good agreement with the data obtained for the free enzyme in solution (Table 1). The kinetic data indicate that immobilization onto capillary has a small effect on the $T c$ GAPDH binding affinity for both substrate and cofactor. The $K_{\mathrm{M}}$ values for the G3P and $\mathrm{NAD}^{+}$are, respectively, 2.6 and 1.2-fold higher than those observed for the free enzyme. Similarly, the $V_{\text {MAX }}$ parameter is 1.7 -fold higher in the IMER format for the cofactor and virtually equivalent for the substrate (Table 1). Conversely, the immobilization procedure has a substantial effect on the HuGAPDH kinetic parameters. As can be observed in Table 1, a significant difference in the $K_{\mathrm{M}}$ values for $\mathrm{NAD}^{+}$and G3P occurred for the immobilized and free HuGAPDH systems. A higher $K_{\mathrm{M}}$ value means lower affinity between the enzyme and substrate, which could be due to the introduction of steric hindrance created by the support towards the active site, as well as by the lack of sufficient enzyme flexibility for binding of the natural ligands during catalysis. ${ }^{27,29,32}$ Additionally, the $V_{\text {MAX }}$ values evaluated for HuGAPDH-IMER are approximately 6-fold higher than those exhibited for the free enzyme (Table 1). Although it is difficult to estimate the extent of the derivatization with glutaraldehyde onto the capillary, the increase in the $V_{\text {MAX }}$ values might be attributed to the presence of a large number of potential reaction sites for covalent coupling with the protein, thereby increasing the amount of active enzyme immobilized onto the capillary. ${ }^{3,29}$ Alternatively, the larger number of lysine residues may allow for double binding on the same tetramer, which would affect the extensive dynamics of the enzyme, required for catalysis.

Table 1. Determination of the kinetic parameters $K_{\mathrm{M}}$ and $V_{\mathrm{MAX}}$ for the free and immobilized human and T. cruzi GAPDHs by nonlinear curve-fitting regression analysis*

\begin{tabular}{lcccc}
\hline GAPDH & \multicolumn{2}{c}{ G3P } & \multicolumn{2}{c}{$\mathrm{NAD}^{+}$} \\
\cline { 2 - 5 } & $K_{\mathrm{M}}\left(\mathrm{mmol} \mathrm{L}^{-1}\right)$ & $V_{\mathrm{MAX}}\left(\mathrm{mmol} \mathrm{L}^{-1} \mathrm{~min}^{-1}\right)$ & $K_{\mathrm{M}}\left(\mathrm{mmol} \mathrm{L}^{-1}\right)$ & $V_{\mathrm{MAX}}\left(\mathrm{mmol} \mathrm{L}^{-1} \mathrm{~min}^{-1}\right)$ \\
\hline T. cruzi & & & & $3.7 \pm 0.1$ \\
free & $0.42 \pm 0.02$ & $3.9 \pm 0.1$ & $0.26 \pm 0.02$ & $6.4 \pm 0.1$ \\
IMER & $0.50 \pm 0.05$ & $4.3 \pm 0.3$ & 2.6 & 1.7 \\
IMER/free & 1.2 & 1.1 & & $0.18 \pm 0.01$ \\
Human & & & $0.75 \pm 0.04$ & $4.2 \pm 0.1$ \\
free & $0.16 \pm 0.02$ & $5.0 \pm 0.2$ & $24 \pm 0.2$ \\
IMER & $3.7 \pm 0.29$ & $33 \pm 7$ & 4.1 & 5.7 \\
IMER/free & 23 & 6.6 & & \\
\hline
\end{tabular}

*The data shown are representative of five independent experiments (mean \pm S.D.). 


\section{free}
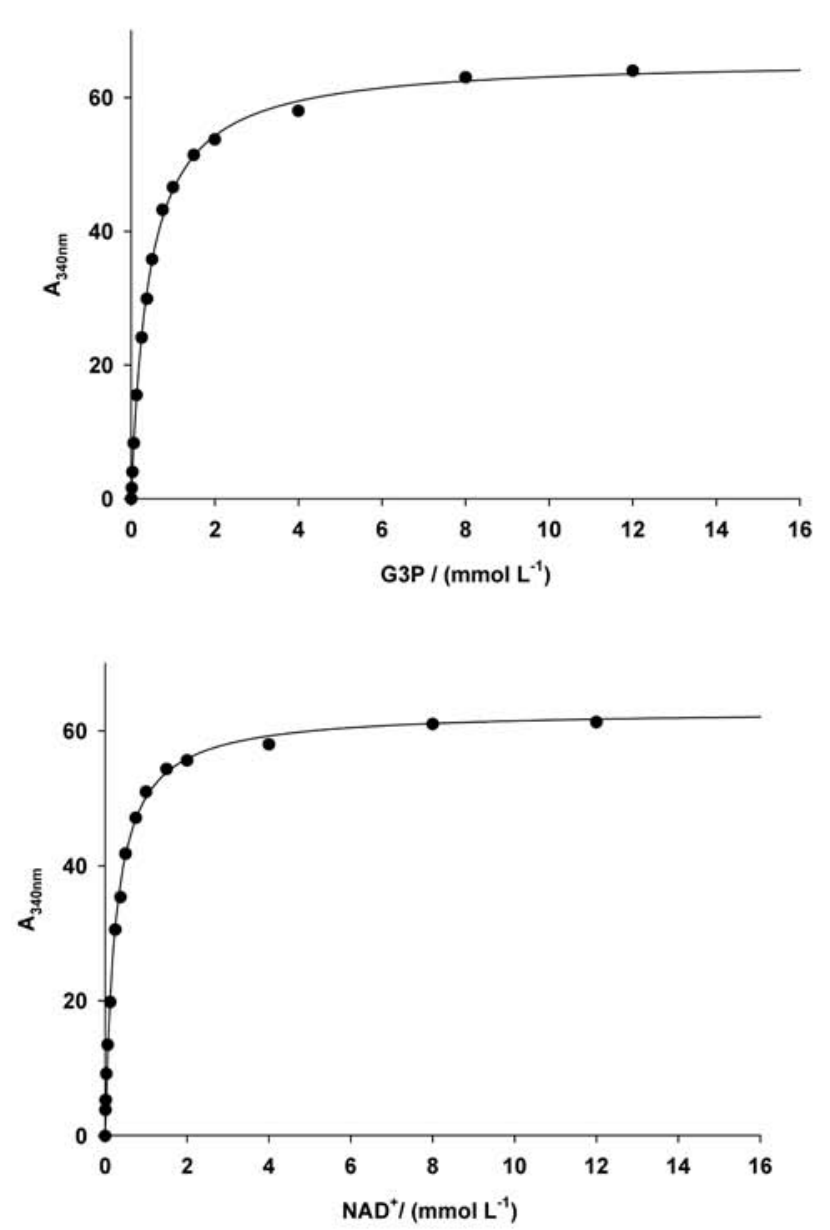

IMER
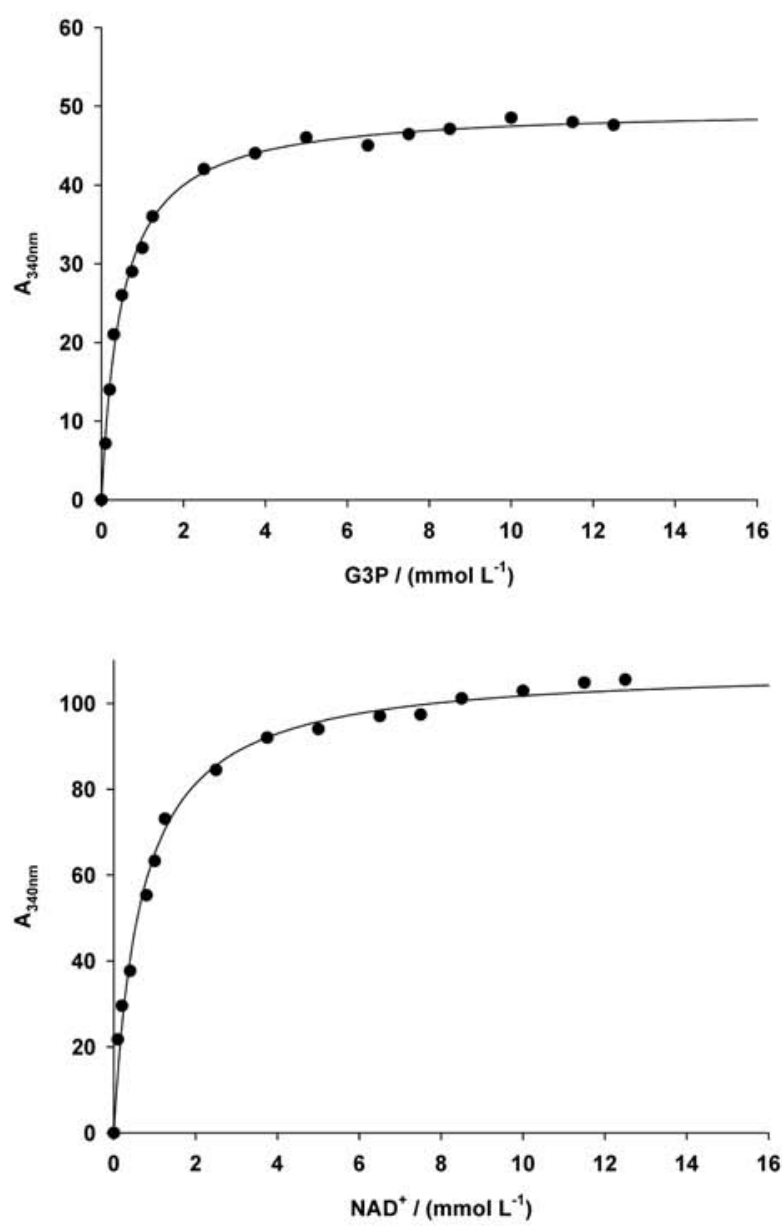

Figure 1. Michaelis-Menten kinetics for T. cruzi GAPDH in free solution and IMER format.

\section{Structural analysis of TcGAPDH and HuGAPDH}

The activity retained after the immobilization procedure indicates that both systems conserved the structural requirements necessary for molecular recognition and binding of the both substrate and cofactor. Based on these important results, a detailed structural analysis of the enzymes was carried out aimed at understanding the factors that determine individual responses to the kinetic parameters upon immobilization on GAPDHs.

The primary sequence alignment revealed that both GAPDHs share approximately 50\% sequence identity, with most of the conserved residues lying on motifs that are required for ligand recognition and catalysis (Figure 3). Despite the low sequence identity, the tertiary and quaternary structures of the enzymes are significantly similar (Figure 4). GAPDH is a homotetramer of molecular mass approximately $150 \mathrm{kDa}$ whose subunits are related to each other by a 222 non-crystallographic symmetry (Figure 4). Each subunit consists of two folding domains. The cofactor binding site (Figure 5) is situated in a cleft formed by the $\mathrm{NAD}^{+}$binding domain (N-terminal domain), which has an $\alpha / \beta$ folding pattern characteristic of the Rossmann fold, with a central parallel $\beta$-sheet covered on both sides by $\alpha$-helices. The substrate binding site (Figure 5) is located in the catalytic domain (C-terminal domain) which folds into an eightstranded antiparallel $\beta$-sheet and two $\alpha$-helices. ${ }^{30,33}$ In order to carry out its biochemical role, the substrate and cofactor must bind to the enzyme active site in a coordinated fashion that induces a remarkable conformational change of the $\mathrm{NAD}^{+}$binding domain along with the shift of several side chains close to the active site. ${ }^{34,35}$

The immobilization methodology employed in this work relies on a pre-activated fused silica capillary with glutaraldehyde, which reacts with primary amino groups on the enzyme structure (i.e., Schiff base formation). ${ }^{23,24}$ Thus, lysine residues play a crucial role in this process with an intensive multipoint covalent attachment being 
free
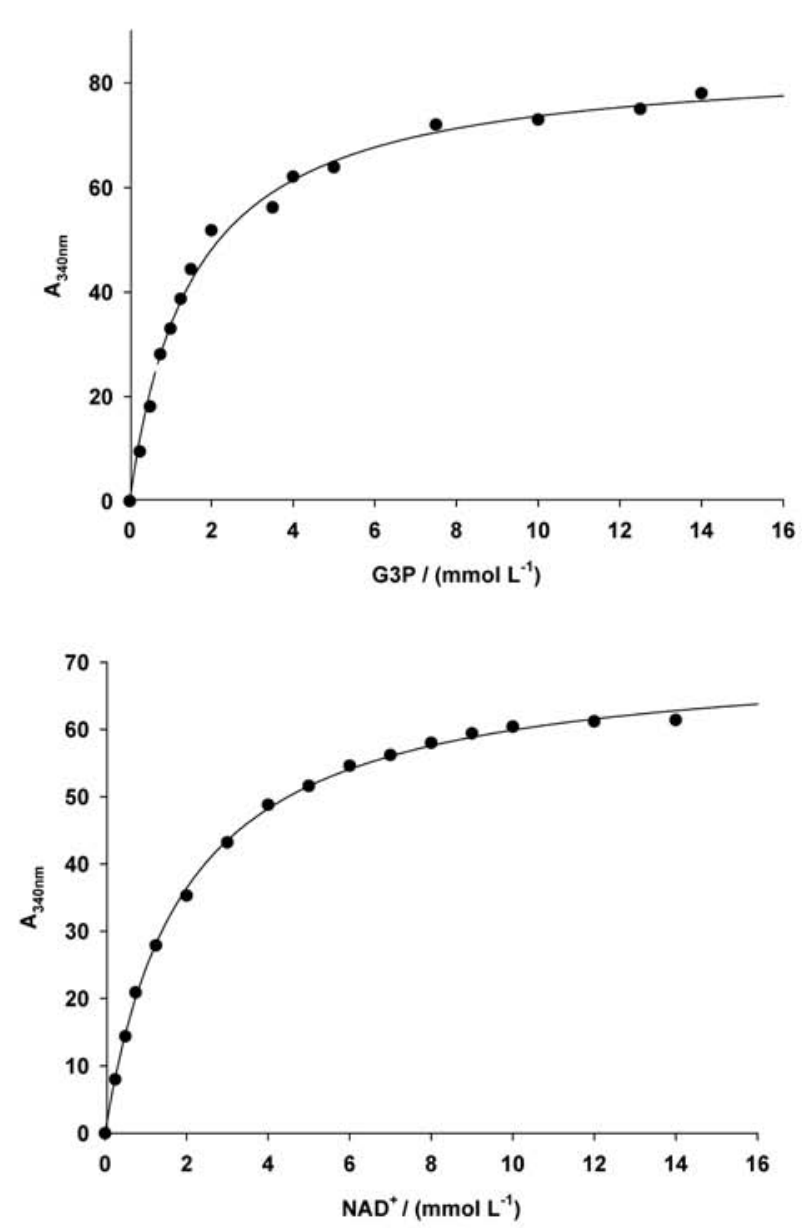

IMER
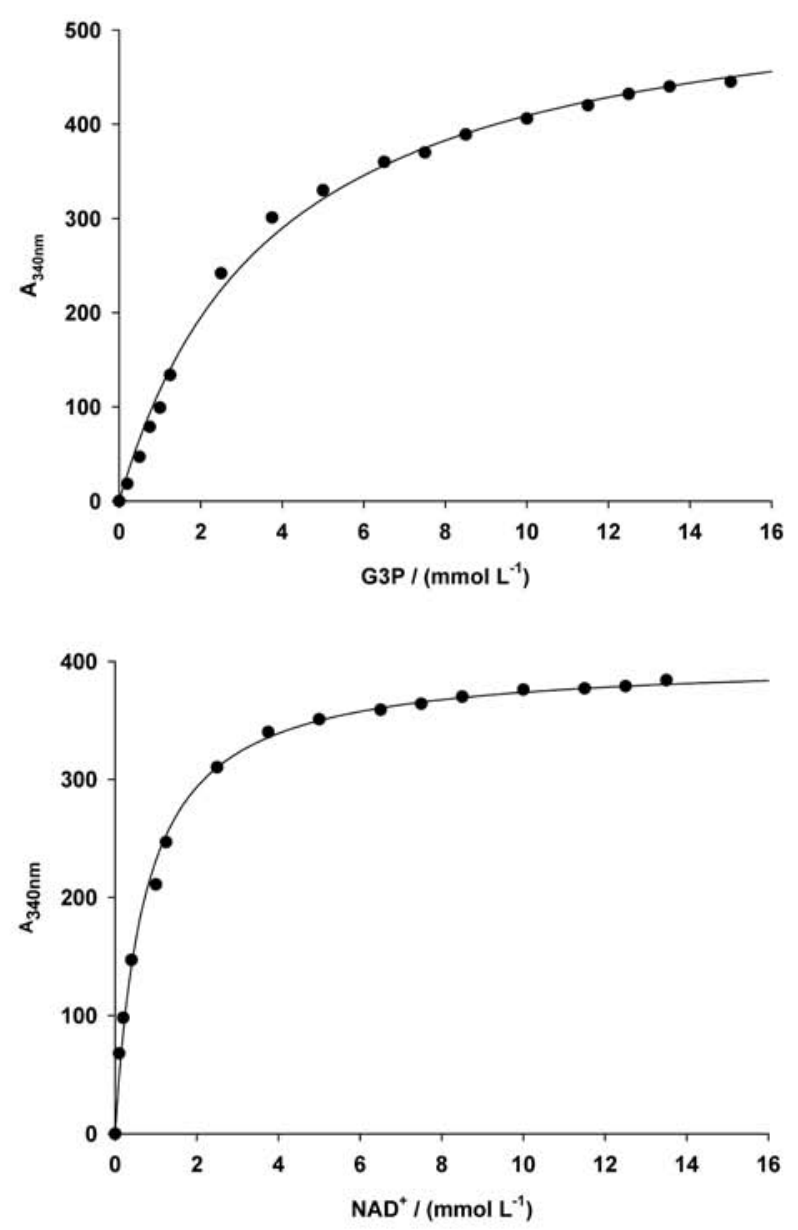

Figure 2. Michaelis-Menten kinetics for human GAPDH in free solution and IMER format.

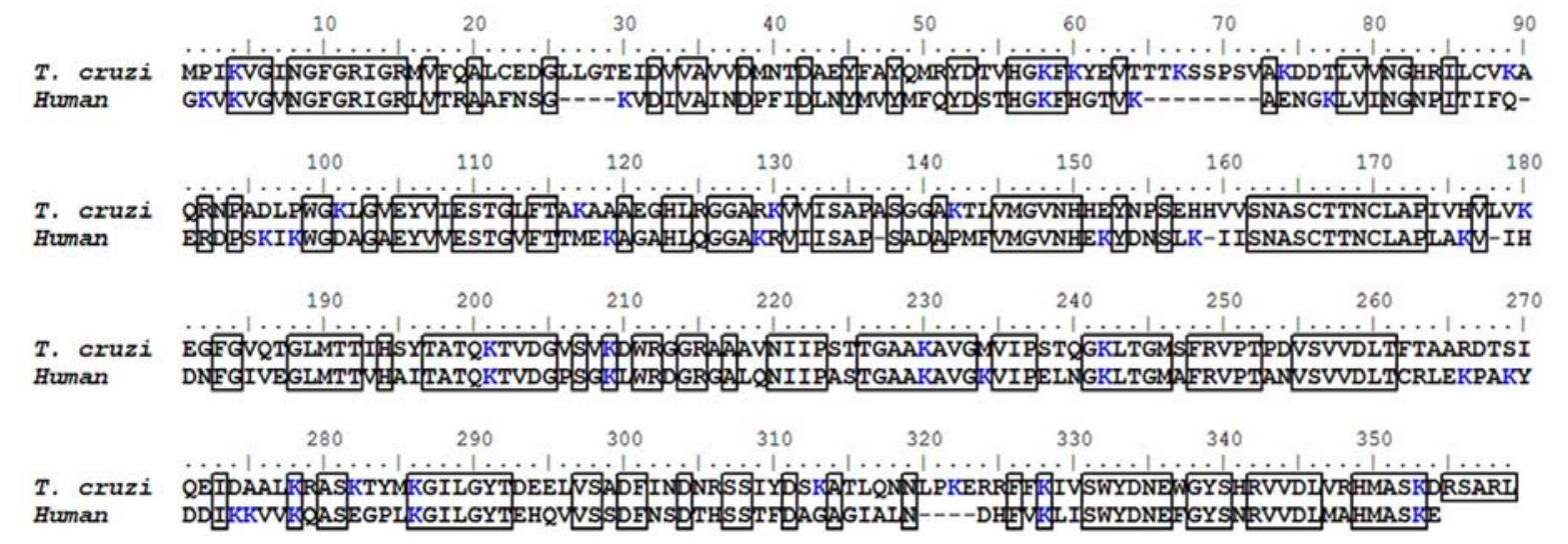

Figure 3. Sequence alignment of T. cruzi and human GAPDH. The numbers above the sequences refer to the parasite enzyme. Conserved residues between species are outlined and lysine residues are depicted in blue (online version).

highly dependent on the amount of amino groups available on the protein surface..$^{36}$ It is worth noting that the lysine amino acids are not involved in the biochemical reaction catalyzed by GAPDH. ${ }^{34,37}$ According to the sequence alignment, $T c \mathrm{GAPDH}$ has 88 lysine residues per tetramer, whereas the human homologue exhibits 104 residues, most of them located in non-conserved regions (Figure 3). The larger number of lysine residues on HuGAPDH suggests 
A

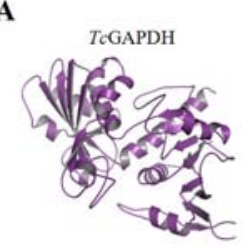

B

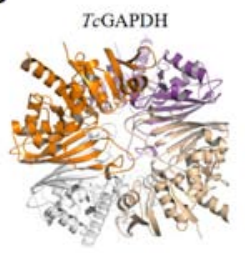

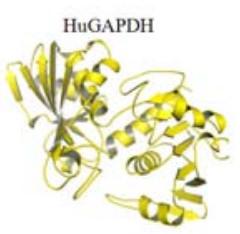

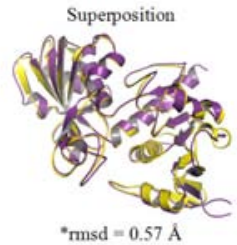

"rmsd $=0.57 \mathrm{~A}$

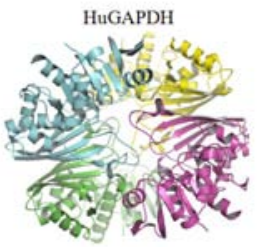

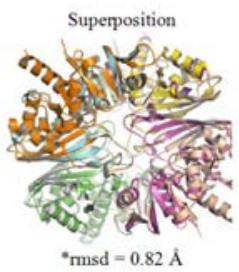

"rmsd $=0.82 \mathrm{~A}$

Figure 4. Tertiary (A) and quaternary (B) structures of the $T c \mathrm{GAPDH}$ (PDB ID, 1QXS) and HuGAPDH (PDB ID, 1ZQN). *rmsd (root mean square deviation for $\mathrm{C} \alpha$ )

A

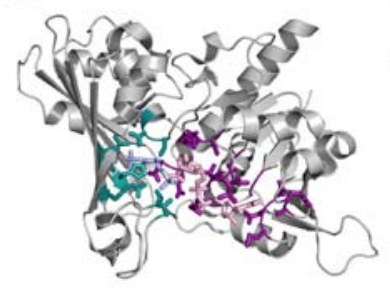

B

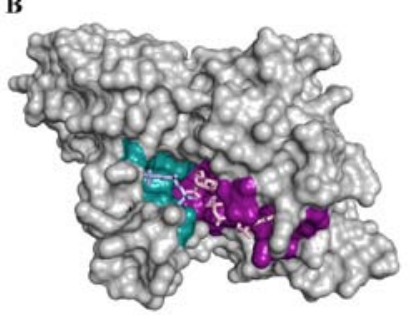

Figure 5. (A) Cartoon representation of GAPDH tertiary structure highlighting the substrate (cyan-online version) and cofactor (purpleonline version) binding sites (PDB ID, 1QXS). Protein residues involved in the binding sites as well as the substrate analog (S70, light blue-online version) and cofactor ( $\mathrm{NAD}^{+}$, light pink-online version) molecules are indicated as stick model. (B) Connolly surface of GAPDH highlighting the substrate (cyan-online version) site and cofactor (purple-online version) binding sites.

a higher probability of covalent attachments, which might lead to an enhanced amount of immobilized enzyme onto capillary. This finding is in good agreement with the increased $V_{\text {MAX }}$ values observed for the HuGADH-IMER (Table 1). Accordingly, the distribution of the lysine residues throughout the structures of the GADPH enzymes indicates that the differences observed in the kinetic parameters for the IMER systems are most probably related to the number and position of the residues modified during immobilization.

A close inspection of the $T c$ and HuGAPDH threedimensional (3D) structures revealed that the vast majority of the lysine residues lye on the solvent accessible surface, therefore, far enough away from the substrate and cofactor binding sites (Figure 5). However, there are two conserved lysine residues (Lys201 and Lys209 in TcGAPDH; and Lys186 and Lys194 in HuGAPDH) located in the proximity of the binding sites of the enzymes. On one hand, the TcGAPDH-Lys201 and HuGAPDH-Lys 186 are buried into the binding pockets (Figure 5), suggesting that the reactive center of those residues might not be

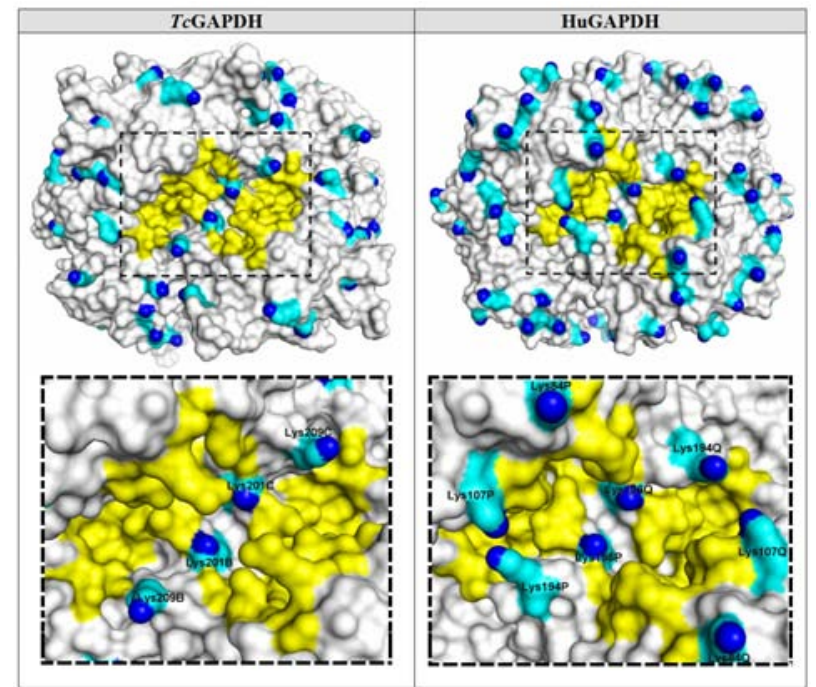

Figure 6. Upper panel: Connolly surface of the $T c$ GAPDH (PDB ID, 1QXS) and HuGAPDH (PDB ID, 1ZQN) quaternary structures. Lower panel: close inspection of the lysine residues close to the binding site of the $T c$ GAPDH (B/C subunits) and HuGAPDH (P/Q subunits). The $\mathrm{B} / \mathrm{C}$ and $\mathrm{P} / \mathrm{Q}$ subunits are equivalent subunits between $T c \mathrm{GAPDH}$ and $\mathrm{HuGAPDH}$, respectively. The lysine residues are indicated in cyan (online version carbon atoms) and blue (online version nitrogen atoms), and the active sites are colored in yellow (online version).

in a permissible distance for a covalent attachment. On the other hand, immobilization through the TcGAPDHLys209 or HuGAPDH-Lys194 residues is likely to affect the access to the active site, leading to electrostatic and steric hindrances, thereby accounting in part for the higher $K_{\mathrm{M}}$ values observed in both IMER systems. Particularly, the human homologue shows two non-conserved lysine residues (Lys84 and Lys107) located in key positions very close to the binding site entrance (Figure 5). Although they are not directly involved in the catalytic (enzymatic) reaction, structural modification of these residues by Schiff base reaction introduces additional bulky elements that could obstruct the access to the active site, which might contribute to the substantial decrease in the affinity of the HuGAPDH-IMER for its substrate and cofactor.

\section{Conformational changes}

Proteins can exist in multiple conformational states. ${ }^{38,39}$ It has been shown that upon binding of the ligand (e.g., substrate, cofactor, inhibitor), the resulting proteinligand complex assumes a new conformation that has lower energy than the protein alone. This mechanism allows the ligand to first gain access to the binding site and as a next step to be surrounded by groups on the enzyme. It is generally accepted that the open domain conformation of the enzyme is favored in the absence of the ligand, and the closed stabilized by the presence of the ligand. ${ }^{38}$ 
Conformational studies performed on the GAPDH structures from several sources identified two preferred conformational states: $\mathrm{NAD}^{+}$-free (open form) and $\mathrm{NAD}^{+}$bound (closed form). ${ }^{40-42}$ These investigations revealed significant protein mobility concomitant with cofactor binding. The $\mathrm{NAD}^{+}$binding domain rotates 3 to 4 degrees relative to the catalytic domain (hinge movement). The induced conformational change can be described as an overall rigid-body rotation of the $\mathrm{NAD}^{+}$binding domain followed by the translation movement of several structural elements. The effect of this rotation is to shield the active site from solvent in the closed form, thereby favoring the catalytic reaction. ${ }^{40}$ In light of this, the covalent linked lysine residues adjacent to the hinge region may restrict the flexibility of the structural components involved in the catalytic mechanism. This structural restriction can further contribute to the decrease in affinity of the GAPDH-IMER systems. Since HuGAPDH exhibits a higher number of lysine residues in the hinge region (aa 23-150), ${ }^{43}$ the effect of immobilization on this homologue might be enhanced, which is in agreement with our experimental data (Table 1).

\section{Conclusion}

The knowledge of the 3D organization is very helpful in the analysis of the kinetic constants and structural differences allowing an integrated study of the experimental and theoretical results in immobilized and free solution enzymatic systems. IMERs are highly versatile tools in drug discovery allowing the screening of a variety of small molecule compounds (from natural products or synthetic libraries) for binding to major molecular drug targets. High stability and reliability are other advantages of the IMER systems, allowing accuracy and reproducibility of the experimental measurements. Although the immobilization procedure has caused a decreased in the affinity of both substrate and cofactor for the GAPDH enzymes, the structural determinants for molecular recognition were not affected. The results indicate that after the immobilization, the G3P and NAD ${ }^{+}$ binding sites are available for the catalytic process to take place. In summary, the combined kinetic and structural analysis provided useful insights into the molecular determinants related to the effects of immobilization on the enzymatic activity.

\section{Supplementary Information}

Supplementary data are available free of charge at http://jbcs.sbq.org.br, as PDF file.

\section{Acknowledgments}

We gratefully acknowledge financial support from the São Paulo Research Foundation (FAPESP) and the National Council for Technological and Scientific Development (CNPq), Brasil

\section{References}

1. Guido, R. V. C.; Oliva, G.; Andricopulo, A. D.; Curr. Med. Chem. 2008, 15, 37.

2. Nie, Y. L.; Wang, W. H.; Chromatographia 2009, 69, S5.

3. Girelli, A. M.; Mattei, E.; J. Chromatogr. B 2005, 819, 3.

4. Marinov, I.; Gabrovska, K.; Velichkova, J.; Godjevargova, T.; Int. J. Biol. Macromol. 2009, 44, 215.

5. Vasileva, N.; Godjevargova, T.; Ivanova, D.; Gabrovska, K.; Int. J. Biol. Macromol. 2009, 44, 190.

6. Bartolini, M.; Greig, N. H.; Yu, Q. S.; Andrisano, V.; J. Chromatogr. A 2009, 1216, 2730.

7. O’Malley, S. M.; Xie, X.; Frutos, A. G.; J. Biomol. Screen. 2007, 12, 117.

8. Sharlow, E. R.; Leimgruber, S.; Yellow-Duke, A.; Barrett, R.; Wang, Q. J.; Lazo, J. S.; Nat. Protoc. 2008, 3, 1350.

9. Guido, R. V. C.; Oliva, G.; Curr. Top. Med. Chem. 2009, 9, 824.

10. Molyneux, D. H.; Adv. Parasitol. 2006, 61, 1.

11. WHO Control of Chagas Disease; World Health Organization: Geneva, Switzerland, 2002; p. 1.

12. Bakker, B. M.; Mensonides, F. I.; Teusink, B.; van Hoek, P.; Michels, P. A.; Westerhoff, H. V.; Proc. Natl. Acad. Sci. U S A 2000, 97, 2087.

13. Verlinde, C. L.; Hannaert, V.; Blonski, C.; Willson, M.; Perie, J. J.; Fothergill-Gilmore, L. A.; Opperdoes, F. R.; Gelb, M. H.; Hol, W. G.; Michels, P. A.; Drug Resist. Updat. 2001, 4, 50 .

14. Cáceres, A. J.; Michels, P. A. M.; Hannaert, V.; Mol. Biochem. Parasitol. 2010, 169, 50.

15. Aronov, A. M.; Suresh, S.; Buckner, F. S.; Van Voorhis, W. C.; Verlinde, C. L.; Opperdoes, F. R.; Hol, W. G.; Gelb, M. H.; Proc. Natl. Acad. Sci. U S A 1999, 96, 4273.

16. Aronov, A. M.; Verlinde, C. L.; Hol, W. G.; Gelb, M. H.; J. Med. Chem. 1998, 41, 4790.

17. Bressi, J. C.; Verlinde, C. L. M. J.; Aronov, A. M.; Shaw, M. L.; Shin, S. S.; Nguyen, L. N.; Suresh, S.; Buckner, F. S.; Van Voorhis, W. C.; Kuntz, I. D.; Hol, W. G.; Gelb, M. H.; J. Med. Chem. 2001, 44, 2080.

18. Guido, R. V. C.; Balliano, T. L.; Andricopulo, A. D.; Oliva, G.; Lett. Drug Discov. Des. 2009, 6, 210.

19. Guido, R. V. C.; Castilho, M. S.; Mota, S. G. R.; Oliva, G.; Andricopulo, A. D.; QSAR Comb. Sci. 2008, 27, 768.

20. Guido, R. V. C.; Oliva, G.; Montanari, C. A.; Andricopulo, A. D.; J. Chem. Inf. Model. 2008, 48, 918. 
21. Van Calenbergh, S.; Verlinde, C. L. M. J.; Soenens, J.; De Bruyn, A.; Callens, M.; Blaton, N. M.; Peeters, O. M.; Rozenskik, J.; Hol, W. G.; Herdewijn, P.; J. Med. Chem. 1995, 38, 3838 .

22. Verlinde, C. L.; Callens, M.; Van Calenbergh, S.; Van Aerschot, A.; Herdewijn, P.; Hannaert, V.; Michels, P. A.; Opperdoes, F. R.; Hol, W. G.; J. Med. Chem. 1994, 37, 3605.

23. Cardoso, C. L.; de Moraes, M. C.; Guido, R. V.; Oliva, G.; Andricopulo, A. D.; Wainer, I. W.; Cass, Q. B.; Analyst 2008, 133, 93.

24. Cardoso, C. L.; Lima, V. V.; Zottis, A.; Oliva, G.; Andricopulo, A. D.; Wainer, I. W.; Moaddel, R.; Cass, Q. B.; J. Chromatogr. A 2006, 1120, 151.

25. Berendsen, W. R.; Lapin, A.; Reuss, M.; Biotechnol. Prog. 2006, 22, 1305.

26. Clark, D. S.; Bailey, J. E.; Biotechnol. Bioeng. 2002, 79, 539.

27. Moaddel, R.; Wainer, I. W.; J. Pharm. Biomed. Anal. 2007, 43, 399.

28. Christopoulos, A.; Nat. Rev. Drug Discov. 2002, 1, 198.

29. Mateo, C.; Palomo, J. M.; Fernandez-Lorente, G.; Guisan, J. M.; Fernandez-Lafuente, R.; Enzyme Microb. Technol. 2007, 40,1451

30. Souza, D. H.; Garratt, R. C.; Araujo, A. P.; Guimaraes, B. G.; Jesus, W. D.; Michels, P. A.; Hannaert, V.; Oliva, G.; FEBS Lett. 1998, 424, 131.

31. Pereira, J. M.; Severino, R. P.; Vieira, P. C.; Fernandes, J. B.; da Silva, M. F.; Zottis, A.; Andricopulo, A. D.; Oliva, G.; Correa, A. G.; Bioorg. Med. Chem. 2008, 16, 8889.
32. Gabrovska, K.; Marinov, I.; Godjevargova, T.; Portaccio, M.; Lepore, M.; Grano, V.; Diano, N.; Mita, D. G.; Int. J. Biol. Macromol. 2008, 43, 339.

33. Ismail, S. A.; Park, H. W.; Acta Crystallogr. D Biol. Crystallogr. 2005, 61, 1508.

34. Castilho, M. S.; Pavao, F.; Oliva, G.; Ladame, S.; Willson, M.; Perie, J.; Biochemistry 2003, 42, 7143.

35. Pavao, F.; Castilho, M. S.; Pupo, M. T.; Dias, R. L.; Correa, A. G.; Fernandes, J. B.; da Silva, M. F.; Mafezoli, J.; Vieira, P. C.; Oliva, G.; FEBS Lett. 2002, 520, 13.

36. Monsan, P.; Durand, G.; Biochim. Biophys. Acta 1978, 523, 477.

37. Nagradova, N. K.; Biochemistry (Moscow) 2001, 66, 1067.

38. Gerstein, M.; Lesk, A. M.; Chothia, C.; Biochemistry 1994, 33, 6739.

39. Teague, S. J.; Nat. Rev. Drug Discov. 2003, 2, 527.

40. Skarzynski, T.; Wonacott, A. J.; J. Mol. Biol. 1988, 203, 1097.

41. Yun, M.; Park, C. G.; Kim, J. Y.; Park, H. W.; Biochemistry 2000, 39, 10702.

42. Shen, Y. Q.; Li, J.; Song, S. Y.; Lin, Z. J.; J. Struct. Biol. 2000, $130,1$.

43. Keating, K. S.; Flores, S. C.; Gerstein, M. B.; Kuhn, L. A.; Protein Sci. 2009, 18, 359.

Submitted: January 6, 2010 Published online: June 18, 2010

FAPESP helped in meeting the publication costs of this article. 


\title{
Structural Insights into the Molecular Basis Responsible for the Effects of Immobilization on the Kinetic Parameters of Glyceraldehyde-3-Phosphate Dehydrogenase from Trypanosoma cruzi and Human
}

\author{
Rafael V. C. Guido, ${ }^{a}$ Carmen L. Cardoso, ${ }^{b}$ Marcela C. de Moraes, ${ }^{c}$ \\ Adriano D. Andricopulo, ${ }^{a}$ Quezia B. Cass ${ }^{*, c}$ and Glaucius Oliva*
}

${ }^{a}$ Laboratório de Química Medicinal e Computacional, Centro de Biotecnologia Molecular

Estrutural, Instituto de Física de São Carlos, Universidade de São Paulo, Av. Trabalhador São-Carlense 400, 13560-970 São Carlos-SP, Brazil

${ }^{b}$ Departamento de Química-Faculdade de Filosofia, Ciências e Letras de Ribeirão Preto, Universidade de São Paulo, Av. Bandeirantes 3900, 14040-901 Ribeirão Preto-SP, Brazil

${ }^{c}$ Departamento de Química, Universidade Federal de São Carlos, CP 676, 13565-905 São Carlos-SP, Brazil

A

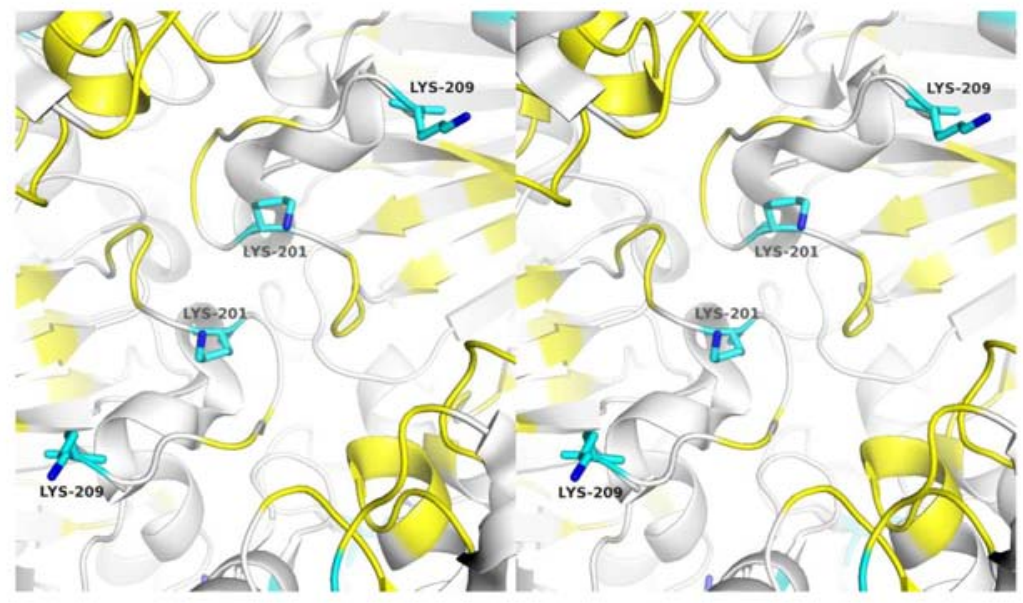

B

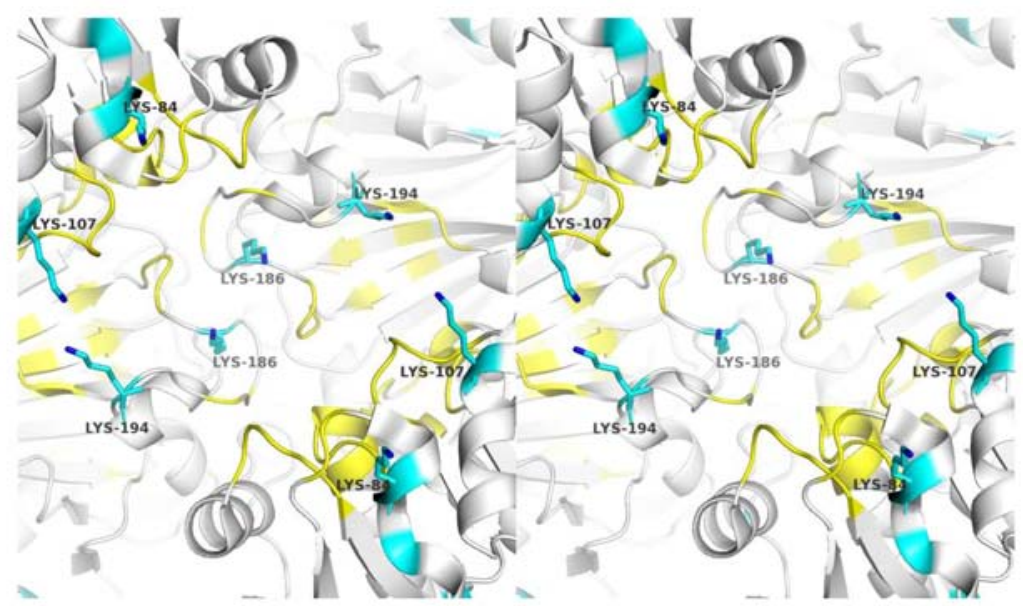

Figure S1. Stereoview of the binding site residues from (A) TcGAPDH and (B) HuGAPDH. The lysine residues are indicated in cyan (carbon atoms) and blue (nitrogen atoms), and the active sites are colored in yellow.

*e-mail: quezia@dq.ufscar.br, oliva@ifsc.usp.br 